\title{
The modal analysis of crack fault gear based on FEM SUN Ye ${ }^{1, a}$, FENG Xiao ${ }^{1, b}$,YIN Fenglong ${ }^{1, c}$, CHEN Silin ${ }^{1, d}$,YANG Dan ${ }^{1, e}$ \\ ${ }^{1}$ Northwest Institute Nuclear Technology, xi'an 710024, China \\ a123sunye@163.com, bfengxiao57372@163.com, cyinfenglongwade@163.com, ${ }^{\mathrm{d}}$ chensilin0413@126.com, ${ }^{\mathrm{e}} \mathrm{pa1013252126.com}$
}

\section{Keywords: FEM; Crack fault gear; Modal.}

Abstract. The finite element analysis model of the crack fault gear with different crack depth is established by the modeling method, and the modal analysis is carried out by the finite element analysis method. In the modal analysis, the results show that the crack will have a certain effect on the stiffness of the gear, and the inherent frequency of the gear will become smaller with the increase of the crack depth.

\section{Introduction}

The operation condition of gear transmission system often directly affects the mechanical equipment's work, and it plays a very important role for the operation of mechanical equipment safety and reliability. The proportion of gear fault is about $60 \%$ in the gear transmission parts, which has become one of the most critical parts in a mechanical transmission. Therefore, it has a very important practical significance for the condition monitoring and fault diagnosis.

A cylindrical spur gear system is considered in this paper, natural frequency and vibration response with normal and crack state of gear by FEM are simulated and calculated on the basis of the gear vibration analysis model with a single freedom.

\section{Modeling of crack gear}

In this paper, the gear model is established by standard plug-in of Solidworks . Its performance parameters are shown in the Table 1.

Table 1 Gear model parameters

\begin{tabular}{|c|c|c|c|c|c|c|c|c|}
\hline $\begin{array}{c}\text { Module } \\
(\mathrm{mm})\end{array}$ & $\begin{array}{c}\text { Center } \\
\text { distance } \\
(\mathrm{mm})\end{array}$ & $\begin{array}{c}\text { Pitch } \\
\text { diameter } \\
(\mathrm{mm})\end{array}$ & $\begin{array}{c}\text { Tooth } \\
\text { thickness } \\
(\mathrm{mm})\end{array}$ & $\begin{array}{c}\text { Number } \\
\text { of teeth }\end{array}$ & $\begin{array}{c}\text { Pressure } \\
\text { angle } \\
\left({ }^{\circ}\right)\end{array}$ & $\begin{array}{c}\text { Whole } \\
\text { depth } \\
(\mathrm{mm})\end{array}$ & $\begin{array}{c}\text { Base } \\
\text { diameter } \\
(\mathrm{mm})\end{array}$ & $\begin{array}{c}\text { Circular } \\
\text { pitch } \\
(\mathrm{mm})\end{array}$ \\
\hline 2.0 & 18 & 36 & 3.14159 & 18 & 20 & 4.5 & 33.8289 & 6.2832 \\
\hline
\end{tabular}

Hairline crack is established in the tooth root and penetrate through the entire gear completely, which is used to simulate the actual crack. Import the model to ANSYS finite element software, and define element type with solid45. The material of gear is cast steel, which elastic modulus $\mathrm{E}$ is $207 \mathrm{GPa}$, Poisson's ratio $\mathrm{V}$ is 0.3 , and density $\mathrm{p}$ is $7800 \mathrm{~kg} / \mathrm{m}^{3}$, smart grid division approach is used to mesh, and meshing refinement is built around the crack. Model is divided 23302 nodes and 118 604 elements. The meshed model is shown in figure 5.

In working condition, it is interference fit between shaft and gear and the gear can rotate around the shaft. So in this paper, the degrees of freedom in $x, y, z$ directions of translation and $x, y$ directions of rotation are constrained within gear surface. 


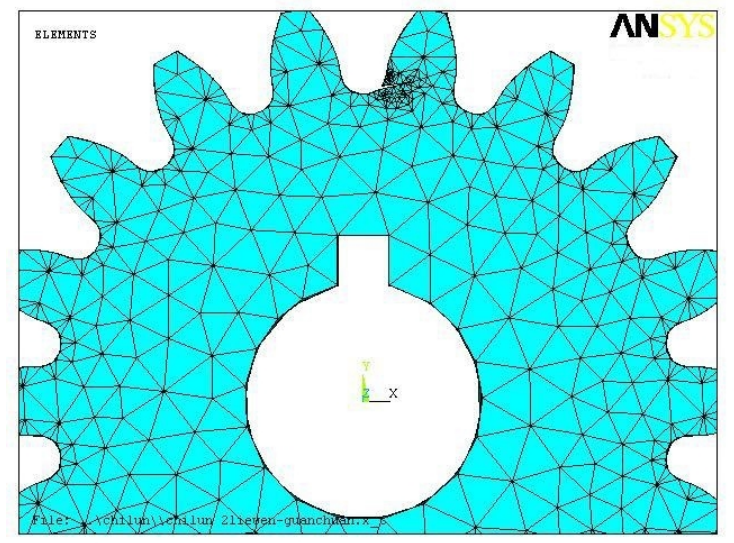

Fig. 1 Meshing refinement of crack gear

\section{Modal Analysis}

The modal parameters (natural frequency and vibration mode) will be significantly changed when the gear is cracked, so it can be considered as an important parameter to diagnose the fault of crack gear.

This paper through the gear model of different depth crack in the tooth root to explore the influence of crack depth on natural frequency. The type of crack gear unit and the method of mesh generation are selected, which are the same as the normal gear.

Under the working condition, the gear and the transmission shaft are in interference fit, and can rotate around the drive shaft. The boundary condition of the gear surface in each node of $\mathrm{X}, \mathrm{Y}, \mathrm{Z}$ direction of the translational degrees and the freedom around $\mathrm{X}, \mathrm{Y}$ axis rotation degree of freedom.

Mode is determined by the inherent characteristics of the system, it has nothing to do with the external load, so it does not need to set the boundary conditions of the load.

In this paper, Block Lanczos method is used to extract gear free vibration modes of five orders with normal and crack gears, which as shown in table 2.

Table 2 Natural frequency of the considered gear

\begin{tabular}{|c|c|c|c|c|c|}
\hline $\begin{array}{c}\text { Natural } \\
\text { frequency/Hz }\end{array}$ & 1 & 2 & 3 & 4 & 5 \\
\hline Normal gear & 29825 & 33887 & 35774 & 37594 & 40941 \\
\hline $\begin{array}{c}\text { Crack-gear } \\
(0.5 \mathrm{~mm})\end{array}$ & 29601. & 33776 & 35402 & 37556 & 40749 \\
\hline $\begin{array}{c}\text { Crack-gear } \\
(1 \mathrm{~mm})\end{array}$ & 29455 & 33671 & 35378 & 37519 & 40668 \\
\hline $\begin{array}{c}\text { Crack-gear } \\
(1.5 \mathrm{~mm})\end{array}$ & 29335 & 33646 & 35283 & 37478 & 40469 \\
\hline $\begin{array}{c}\text { Crack-gear } \\
(2 \mathrm{~mm})\end{array}$ & 29269 & 33592 & 35163 & 37409 & 40382 \\
\hline $\begin{array}{c}\text { Crack-gear } \\
(2.5 \mathrm{~mm})\end{array}$ & 29134. & 33504 & 35129 & 37365 & 40330 \\
\hline \begin{tabular}{c} 
Crack-gear(3mm) \\
\hline
\end{tabular} & 27824 & 29798 & 33570 & 35181 & 37460 \\
\hline
\end{tabular}


Seen from Table2, natural frequency of crack gears is significantly reduced than the normal value.

Consider the formulaError! Reference source not found., where $\omega$ is the natural frequency, $\mathrm{K}$ is the stiffness, $\mathrm{M}$ is the mass. When a crack appears, the mass of the gear does not change obviously, so the formula can tell that the existence of cracks reduces gear's stiffness.

To further study the effects with crack on dynamics component, the paper makes a more in-depth study on gear cracks. The simulation aims at crack gears with different depth primarily (crack depth are from small to large, a total of six data), and natural frequency of five orders are extracted for each gears. This paper draws the trends of natural frequency with crack depth changes. The trends of natural frequency of cracks with different depths are shown in figure 2, in which the horizontal axis represents the crack depth and vertical axis represents the natural frequency ratio of crack gear and normal gear.

It can be seen from figure 2, with the crack depth increase, the natural frequency shows an obvious downward trend, and the first several natural frequencies are greatly influenced by crack depth especially.

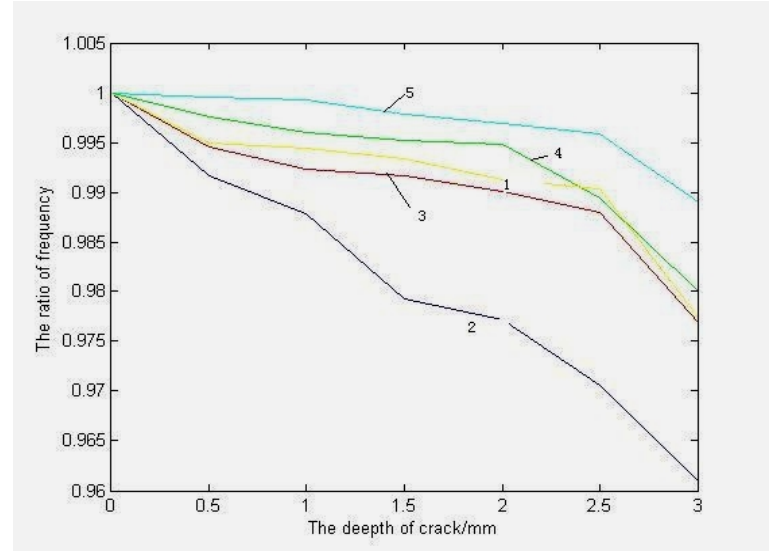

Fig. 2 The trends of natural frequency with different crack depths

Figure 3 IS for the different depth of the crack of the vibration mode, the dotted line indicates the original displacement.

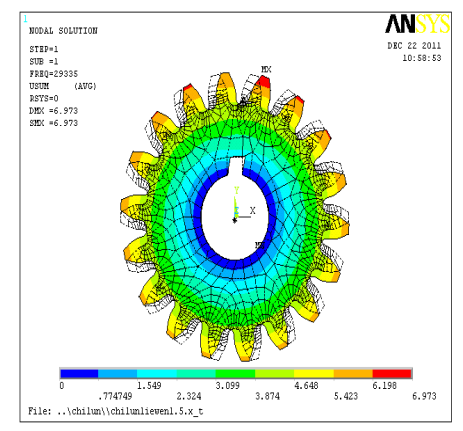

(a) 1 order vibration mode of $1 \mathrm{~mm}$ crack

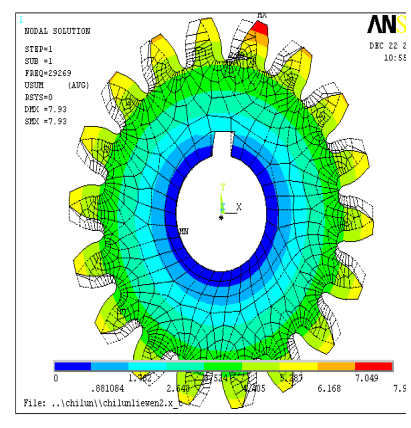

(b) 1 order vibration mode of $2 \mathrm{~mm}$ crack 


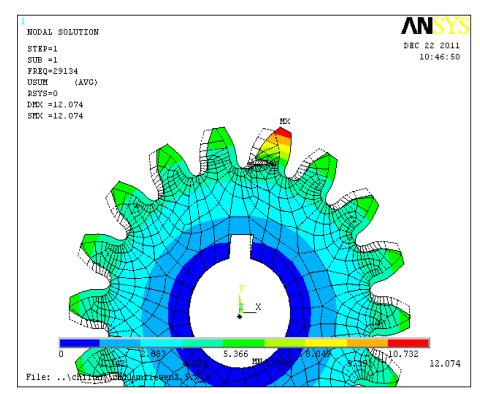

(c) 1 order vibration mode of $2.5 \mathrm{~mm}$ crack

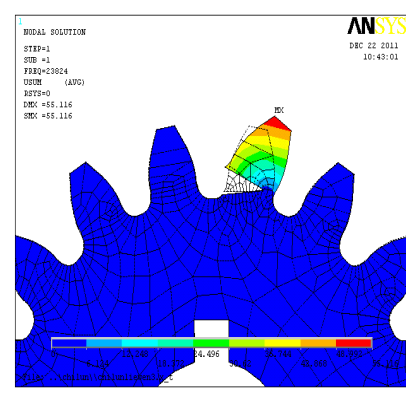

(d) 1 order vibration mode of $3 \mathrm{~mm}$ crack

Fig.3 The modules of different crack depths

Can be seen from Figure 3, the maximum deformation of gear tooth crack always occurs in existence, which further shows that the existence of the crack, the tooth strength is low, forcing the larger cracks in tooth deformation and displacement, and with the increase of the crack depth, crack and deformation are the main influence factor of gear.

As can be seen from Figure 3, when the $2 \mathrm{~mm}$ crack, although the maximum displacement occurs in the crack teeth, but there is no obvious tooth fracture tendency. But in the $2.5 \mathrm{~mm}$, the gear has a tendency to fracture, this phenomenon is more obvious in the $3 \mathrm{~mm}$. Analysis shows that with the increase of the crack depth, the gear will eventually be broken. This is also shown in Figure 3 the natural frequency of the various orders of the crack depth $2.5 \mathrm{~mm}$ is a significant turning point.

\section{Conclusion}

In this paper, the model of gear and gear with crack is established in the finite element software, and the dynamic characteristics of the gear and the crack fault gear are simulated and analyzed. Through the comparative analysis, we can draw the following conclusions:

1 the static characteristics (natural frequency, vibration mode and so on) of the gear teeth with cracks are analyzed, and the influence of the crack size on the static characteristics of the gear is discussed. It is pointed out that the crack size has influence on the natural frequency and vibration mode of the gear, when the natural frequency is decreased and the vibration mode is changed. And the stress also changed, and the dynamic characteristics of the gear with no crack is completely different.

2. The response results with different nodes provide a certain basis for the optimization of sensor's measuring point.

\section{References}

[1] LI Runfang, WANG Jianjun. Dynamics of gear system: vibration, impact, noise [ M ] . Beijing: Science Press, 1997. (In Chinese)

[2]YANG Cheng- yun , LIN Teng- jiao , LI Run- fang, et al. Response analysis of speed increase gearbox system in dynamic excitation $[\mathrm{J}]$. Journal of Chongqing University: Natural Science Edition,2002,25(2) : 15-18 .

[3] ZHOU Changjiang, ZHONG Zhhua, TANG Jinyuan . Research on the loading point of bending strength calculation based on gear error and flexibility [ $\mathrm{J}$ ] . Journal of Hunan University: Natural Sciences, 2007, 34( 7) : 35 -38. (In Chinese) 
[4] ZHANG Xiqing, XIANG Changle, LIU Hui. Identification and validation of test modal parameters of gearbox housing in a certain tracked vehicle [J]. Journal of JilinUniversity (Engineering and Technology Edition), 2002,22(1):55-57. (In Chinese)

[5] J H Kuang,Y T Yang. An Estimate of Mesh Stiffness and Load Sharing Ratio of a Spur Gear Pair [J]. ASME Journal of International Power Transmission and Gearing Conference,1992(1);1-9

[6] Tavakoli M S, Houser.D.R Optimum profile Modifications for the Minimize-lion of Static Transmission Errors of Spur Gears[J]. ASME J. of Mechanisms, Transmissions, and Automation in Design, 1986,108:86-94. 